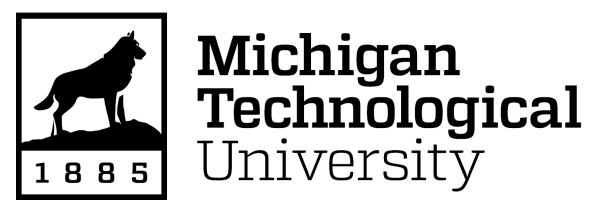

Michigan Technological University Digital Commons @ Michigan Tech

$10-2015$

\title{
SEM of service quality to predict overall patient satisfaction in medical clinics: a case study
}

Dana M. Johnson

Michigan Technological University, dana@mtu.edu

Roberta S. Russell

Virginia Polytechnic Institute and State University

Follow this and additional works at: https://digitalcommons.mtu.edu/business-fp

Part of the Other Business Commons

\section{Recommended Citation}

Johnson, D. M., \& Russell, R. S. (2015). SEM of service quality to predict overall patient satisfaction in medical clinics: a case study. The Quality Management Journal, 22(4), 18-36. http://doi.org/10.1080/ 10686967.2015.11918448

Retrieved from: https://digitalcommons.mtu.edu/business-fp/26

Follow this and additional works at: https://digitalcommons.mtu.edu/business-fp

Part of the Other Business Commons 
DANA M. JOHNSON, MICHIGAN TECHNOLOGICAL UNIVERSITY ROBERTA S. RUSSELL, VIRGINIA POLYTECHNIC INSTITUTE AND STATE UNIVERSITY

This study analyzed patient satisfaction surveys to determine wbich process attributes affect overall patient satisfaction. The authors conclude that the strongest impact is the care provider's interaction with the patient. Healthcare providers/practitioners value business analytics as a means to focus and redirect their continuous improvement efforts and to encourage appropriate provider bebavior. The data for this research were gathered from patient satisfaction surveys from 18 diverse medical clinics in a rural, Midwestern U.S. bealthcare system. Overall patient satisfaction was measured by four separate variables. Quality service was measured by five dimensions and related constructs. All were measured tbrough the use of a five-point Likert-scaled survey. Confirmatory factor analysis and structural equation modeling were applied to identify the factors that impact overall patient satisfaction at the clinics. This research, and the surveys from which the data were derived, focus on process dimensions of service quality, rather than the technical aspects of the bealthcare delivery system.

Key words: factor analysis, bealtbcare service quality, patient satisfaction, structural equation modeling

\section{INTRODUCTION}

Revenues from outpatient services are expected to meet or exceed revenues from inpatient acute care services in the near future (Carlucci, Renna, and Schiuma 2013). In the outpatient setting, the ability to serve an expanding population of patients while controlling costs and increasing quality of care means attracting and retaining patients for the long term. Patient satisfaction is now an integral part of quality of care assessments for hospitals, and is increasingly being measured in clinics and other healthcare settings as well (Mannon 2014). However, the preponderance of analysis and research in patient satisfaction addresses quality in an acute care hospital setting (Andaleeb 2001; Badri and Attia 2008; Carter, Lonial, and Raju 2010). A gap in the literature exists in predicting patient satisfaction for medical clinics, and in identifying and understanding the different attributes of service quality for patients who maintain a continuing relationship with a clinic or physician's office.

This research addresses these shortcomings by analyzing patient satisfaction surveys from the medical clinics of a rural Midwestern healthcare organization. Qin et al. (2014) addressed the issue by surveying patients in an urgent care setting. The authors' research not only looks at urgent care, but also at a more diverse group of 18 medical clinics to include family practice and specialty outpatient clinics (OB/GYN, orthopedics, and so on). The patient satisfaction survey was constructed and administered in 2012 by Press Ganey, a certified healthcare assessment vendor. This study proposes and tests a structural equation model (SEM) to identify factors that impact 
patient satisfaction. The goal of this research is twofold: 1) to gain a greater understanding of the factors that drive overall patient satisfaction in medical clinics; and 2) to explore how metrics of patient satisfaction can foster continuous process improvement efforts.

In the sections that follow, the authors review the literature on patient satisfaction, develop a conceptual model and hypotheses for drivers of patient satisfaction, analyze the patient satisfaction surveys and present the model results, and discuss the implications of this study and future research.

\section{LITERATURE REVIEW}

Prior research and how it frames this study is important to identifying and understanding the concept of service quality as it relates to patient satisfaction. The authors begin with a study by Dagger, Sweeney, and Johnson (2007) that classified service quality in the healthcare setting into interpersonal service quality, administrative service quality, and technical service quality. Interpersonal service quality consists of manners, communication, and relationships. Manners are defined as attitudes and behaviors of service providers in a strictly service setting (Carson, Carson, and Roe 1998; Dagger, Sweeney, and Johnson 2007). Communication emphasizes the interactive nature between cocreators, the degree of interaction, and the balance of two-way exchanges (Dagger, Sweeney, and Johnson 2007). In a medical office setting, relationships are an aspect of interpersonal quality, which are referred to as emotional-relational aspects of quality, but which are usually only superficially assessed (Sanchez-Hernandez, Houseman, and Ryan 2009).

\section{Defining Quality}

Administrative service quality facilitates the production of core services, which are value added to the customer's service use or purpose (McDougall and Levesque 1994). Dagger, Sweeney, and Johnson (2007) reported that there are three major dimensions of administrative service quality: timeliness, operation, and support. Timeliness relates to every aspect associated with time and includes time to wait to: schedule an appointment (on telephone or in person); check in at registration, in reception area, in room before seeing the practitioner, in room after seeing the practitioner; and check out and leave the medical office. Operation relates to the administrative facilitation of the core service function and the efficiency of the related processes, either direct or indirect. Added value to core services best describes the support service dimension (Dagger, Sweeney, and Johnson 2007). An example may be tests performed or referrals to specialists. Other researchers have used the term functional service quality to describe a combination of interpersonal and administrative service quality.

Functional quality is also used to describe interpersonal and administrative service quality, which describe how the services are delivered as defined by patients' perceptions and attitudes regarding the interactions that take place during the service delivery (Brady and Cronin 2001; Canel and Fletcher 2001). Functional quality is directly linked to process management, which represents the methodological and behavior practices associated with actions to achieve results (patient satisfaction) (Douglas and Fredendall 2004; Haywood-Farmer 1988).

Technical service quality addresses customer perceptions of expertise (technical competence) and outcome (treatment working as planned) (Andaleeb 2001; Brady and Cronin 2001; Canel and Fletcher 2001; Dagger, Sweeney, and Johnson 2007). Technical competence can be measured with clinical results or, in the case of patient surveys, can be judged by years of experience, expert opinions of other practitioners, years of education, independent reporting agencies, specialty, perceptions of other patients, and previous patient experiences with the practitioner. Although some attributes are objective in nature (that is, years of experience, years of education), there may be a high level of subjectivity in arriving at the overall assessment of technical quality. Anecdotally, some patients judge technical quality on the basis of pleasantness, friendliness, and positive interactions with the practitioners, which may skew their ability to rationally discern technical quality (Koenig and Kleinsorge 1994; Sanchez-Hernandez, Houseman, and Ryan 2009).

Research suggests that patients are more strongly influenced by interpersonal/functional service 
quality than by technical service quality (Koenig and Kleinsorge 1994; Sanchez-Hernandez, Houseman, and Ryan 2009). Based on these findings and definitions of service quality, the focus in this study is on interpersonal service quality and administrative service quality dimensions and related constructs. The overarching concept to generalize the aspect of service quality is to refer to it as process quality as opposed to technical quality. The study will emphasize and focus on process quality.

\section{Patient Satisfaction}

Studies suggest that individual attention, helpfulness, courtesy, and promptness have a significant effect on satisfaction (Babbar and Koufterous 2008). In the context of the earlier definitions, these attributes describe interpersonal service quality or the "personal touch" associated with the service experience (Babbar and Koufterous 2008; Soteriou and Chase 2000). The soft side of the service may play a greater role in overall patient satisfaction than technical service quality (Choi et al. 2004).

Patient satisfaction survey results are used to investigate the level of quality healthcare provided (Ford, Bach, and Fottler 1997; Lin and Kelly 1995). Because patients often infer the level of technical quality based on interpersonal and administrative service quality dimensions and constructs, weight is given to the out-. come of these survey results (Badri and Attia 2008). It may be challenging to measure technical service quality because of the low volume, high variety paradigm that characterizes the service provided and the level of specialization involved in each transaction. Another issue is that waiting time influences perceptions of overall patient satisfaction (Brady and Cronin 2001).

Although some studies do not differentiate between service quality and patient satisfaction, they are indeed different. Evidence suggests that perceived service quality influences patient behavior and that patient satisfaction is the overall metric or outcome variable of the service (Andaleeb 2001; Carson, Carson, and Roe 1998). "This ambiguity is a result of limited healthcare sector research regarding patient's perceptions of dimensions of service quality" (Carlucci, Renna, and Schiuma 2013, 39). Functional or process service quality, as interpreted by the patient's perspective, offers healthcare providers with an attractive strategic framework (Choi et al. 2004).

\section{Prior Research}

In an era of increasing demand for healthcare services and reforms in healthcare administration designed to control costs and increase quality of care, patient satisfaction is key to attracting and retaining patients. The high cost of healthcare has increased consumer demand for improved outcomes and for organizations to elevate overall patient satisfaction. Gathering data through personal interviews and/or surveys is an important means to gauge patient satisfaction and to adjust quality metrics to improve the overall patient experience (Mannon 2014). Numerous studies on patient satisfaction and outcomes have been published in various academic journals, including medical journals for specific medical specialties (Chang et al. 2006; Urden 2002; Zandbelt et al. 2004); healthcare journals with emphasis on clinical or technical quality (Tucker 2002); and marketing journals with emphasis on SERVQUAL and similar service models (McDougall and Levesque 1994; Brady and Cronin 2001; Parasuraman, Zeithaml, and Barry 1988; Kilbourne et al. 2004). Additionally different analytics have been applied to analyze patient satisfaction data, including optimization (Soteriou and Chase 2000), regression (Hall and Dornan 1988; Zandbelt et al. 2004), factor analysis (Tucker 2002; Kilbourne et al. 2004), conjoint methodology (Carman 2000), analytic hierarchy process (AHP) (Buyukozhan, Cifci, and Guleryuz 2011), fuzzy set theory (Wu, Hsiao, and Kuo 2004), neural networks (Carlucci, Renna, and Schiuma 2013; Behara, Fisher, and Lemmink 2002), and SEM (Ancarani, DiMauro, and Giammanco 2011; Marley, Collier, and Goldstein 2004; Scotti, Harmon, and Behson 2007; Cengiz and Kirkbir 2007; Choi et al. 2004). Many of the prior studies have focused on inpatient hospital stays (Andaleeb 2001; Badri and Attia 2008; Carter, Lonial, and Raju 2010) or specialized medical practices (Geberemichael et al. 2011; Mazor et al. 2002; Maddigan, Majumdar, and Johnson 2005; Carman 2000; Kilbourne et al. 2004). 
Figure 1 Mediators in overall patient satisfaction relationships

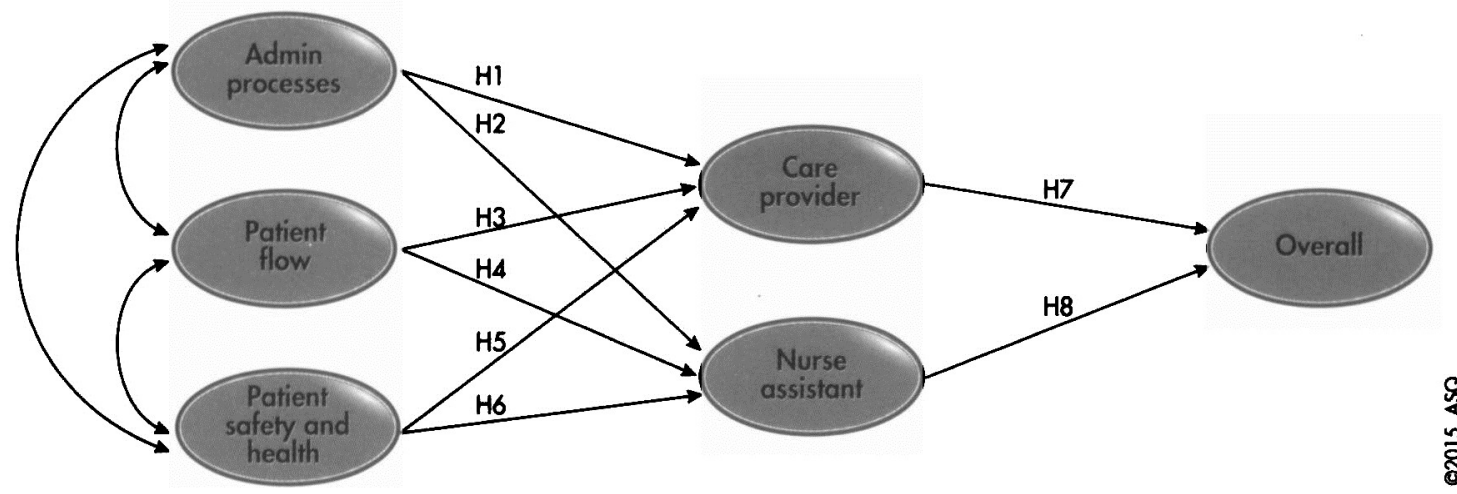

In addition to improving overall quality outcomes, effective use of patient satisfaction metrics may create a competitive advantage (MacInnes 2014). The voice of the patient using data and business analytics allows decision makers to make better informed decisions and executives to craft more compelling strategies. The authors' study extends the work of Qin et al. (2014) as well as insights from inpatient hospital stays and specialty medical practice patient satisfaction studies.

\section{DATA COLLECTION AND ANALYSIS}

This research focuses on a rural, Midwestern U.S. healthcare organization and their diverse medical clinics. The medical clinics include family practice, urgent care, and specialty clinics (that is, $\mathrm{OB} / \mathrm{GYN}$, pediatrics, and so on) for a total of 18 different locations. The patient satisfaction surveys were created and administered by a certified third-party vendor, Press Ganey. They consist of 36 attitudinal questions based on a five-point Likert scale. A number of analytical techniques were employed to arrive at a predictive model, including descriptive statistics, regression, and SEM. SEM is a statistical tool to test the relationship proposed in a parsimonious model. Because latent constructs are the basis of the model, SEM examines the interactions with fewer variables than if all the observed variables were included (Cheng 2001). The computations are based on simultaneous regression of the endogenous variables of the hypothesized model and assessed by goodness of fit measures (Cheng 2001).
The five-factor latent variable model enabled the authors to predict overall patient satisfaction as mediated by care providers and nurses/assistants. Evidence suggests that patient satisfaction is more dependent on the care provider than the nurse/assistant. The results were shared with executive management at UP Health Systems Portage to better understand how practitioners may benefit from using additional information to improve patient satisfaction.

\section{CONCEPTUAL MODEL}

The authors propose a conceptual model (see Figure 1) for patient satisfaction and apply multivariate techniques to empirically test predetermined relationships. Service quality and patient satisfaction are unique constructs measured through a number of distinctive dimensions (Choi et al. 2004). The constructs of administrative processes, patient flow, and patient safety and health indirectly impact overall patient satisfaction (referred to as "overall" in the visual depiction), as shown in the proposed model (see Figure 1). They are mediated by the constructs care provider and nurse/assistant, which have a direct impact on overall patient satisfaction. The model seeks to find the level of influence of administrative processes, patient flow, and patient safety and health on care providers and nurses/assistants, and the latter's impact on overall patient satisfaction.

A mediator accounts for the relationship between the predictor and criterion (Baron and Kenney 1986). In outcomes research it is common to have mediating 
variables, variables that describe the process by which intervention achieves its effect or outcome (MacKinnon 2012). The outcome in the authors' research is overall patient satisfaction. Satisfaction with care provider and nurse/assistant drive overall patient satisfaction. Administrative processes, patient flow, and patient safety and health do not directly impact overall patient satisfaction. In fact, without the care provider and nurse/assistant, the patient's visit would not occur, and therefore, there would be no reason to measure overall patient satisfaction. However, if the processes preceding or in corroboration with the patient's visit did not occur, then there would be no service transaction. In this case, the transaction is the patient's visit.

Administrative processes, patient flow, patient safety and health, care provider, and nurse/assistant capture the affective dimensions that relate to the emotional and social aspects of the individual regarding the patient's visit or the service transaction (Cengiz and Kirkbir 2007). In the model proposed in Figure 1, the mediators are the healthcare providers characterized as care provider and nurse/assistant.

Care provider is defined as the primary care physician, physician's assistant, nurse practitioner, or specialist physician who will diagnose the patient and prescribe some form of treatment and/or follow-up visit (Russell, Johnson, and White 2014). Patient satisfaction with care provider relates to several dimensions such as the physician's interpersonal skills, length of service, information provided during the visit (that is, diagnosis, medication instructions, follow-up care, and so on), communication with patients, and friendliness/courtesy (Chahal and Mehta 2013). Research has explicitly noted the importance of communication in the overall assessment of patient satisfaction as it relates to the primary care provider (Naidu 2009). Concern for a patient's welfare and expressing concern while providing treatment likely will impact patient confidence in the care provider, which in turn impacts overall patient satisfaction (Chahal and Sharma 2004). Listening would appear to be an important attribute and is implicit in several of the questions related to care provider.

Nurse/assistant is defined as the initial healthcare professional seen by patients during their patient flow whose primary role is to gather information regarding the purpose of the visit and to conduct preliminary tests such as weight, height, blood pressure, temperature, and so on. (Russell, Johnson, and White 2014). This may be a nurse, certified medical assistant, certified nurse assistant, or comparable type of position. Patient satisfaction toward nursing/assistant care is typically determined by the empathy, friendliness, courtesy, and feeling that they are truly being cared for (Chahal and Mehta 2013).

Administrative processes includes a number of different dimensions, with most activities occurring prior to the patient's visit. Upon making an appointment, patients are interested in the convenience of the office hours at the clinic (Chahal and Mehta 2013). Some of these administrative processes variables are measurable (hours of operation, time to reach office, and so on) and some are termed "soft" variables such as courtesy, helpfulness, and ease (Russell, Johnson, and White 2014). Having access to healthcare when needed is important (Naidu 2009).

Patient flow describes the activities, surroundings, and time spent in the waiting room or exam room prior to or between interactions with the healthcare provider (Russell, Johnson, and White 2014). It also includes keeping patients informed throughout their visit regarding wait time before and after entering the exam room (Chahal and Mehta 2013). This factor is a major focus of process improvement (Drupsteen, Van der Vaart, and Van Donk 2013).

Patient safety and bealth has been referred to by other researchers as safety climate. (Boyer, Gardner, and Schweikhart 2012; Vogus, Sutcliffe, and Weick 2010). Included in this factor would be facility safety and cleanliness (Chahal and Mehta 2013), as well as patient-centered policies and concerns such as protecting patient privacy, securing patient records and confidentiality, and keeping patients safe from contamination, infections, or illnesses (Russell, Johnson, and White 2014).

Overall patient satisfaction captures the logic dimension of the outcome of the service quality of the transaction or the patient's visit (Cengiz and Kirkbir 2007). Patient satisfaction survey results are used to investigate the level of quality healthcare provided (Lin and Kelly 1995; Ford, Bach, and Fottler 1997). Because 
patients often infer the level of technical quality based on the interpersonal and administrative service quality dimensions and constructs, weight is given to the outcome of these survey results (Badri and Attia 2008).

Although some studies do not differentiate between service quality and patient satisfaction, they are indeed different. Evidence suggests that perceived service quality influences patient behavior and overall patient satisfaction is the overall metric or dependent or outcome variable (Andaleeb 2001; Carson, Carson, and Roe 1998). "This ambiguity is a result of limited healthcare sector research regarding patient's perceptions of dimensions of service quality" (Carlucci, Renna, and Schiuma 2013, 39).

\section{RESEARCH QULSTIONS AND HYPOTHESES}

As a result of the literature review and identified gaps, there are several research questions regarding what impacts overall patient satisfaction.

1. Does service quality as measured by patient perceptions of administrative processes, patient flow, and patient safety and health influence their views of care provider and nurse/assistant?

2. Does service quality as measured by patient perceptions of care providers and nurse/assistant impact overall patient satisfaction?

These research questions have led to the development of the following hypotheses, as shown in Figure 1.

\section{Nediating Role of Care Provider}

The relationship between service quality and overall patient satisfaction may be mediated by the care provider, which leads to the following:

- H1: The relationship between administrative processes and overall satisfaction is mediated by the care provider.

- H3: The relationship between patient flow and overall satisfaction is mediated by the care provider.

- H5: The relationship between patient safety and health and overall satisfaction is mediated by the care provider.
- H7: The care provider positively impacts overall patient satisfaction.

\section{Mediating Role of Nurse/Assistant}

The relationship between service quality and overall patient satisfaction is mediated by the nurse/assistant, which leads to the following:

- H2: The relationship between administrative processes and overall satisfaction is mediated by the nurse/assistant.

- H4: The relationship between patient flow and overall satisfaction is mediated by the nurse/assistant.

- H6: The relationship between patient safety and health and overall satisfaction is mediated by the nurse/assistant.

- H8: The nurse/assistant positively impacts overall patient satisfaction.

Data from surveys and multivariate analysis were applied to test these hypotheses.

\section{METHODOLOGY}

\section{Data Collection}

A survey created by Press Ganey for UP Health Systems Portage Medical Practice Group was the data gathering instrument. The survey consisted of a total of 36 attitudinal questions. Thirty-two questions focused on five main areas of process quality (Marley, Collier, and Goldstein 2004) that feed into an overall assessments of the care provided. Process quality relates to "how" service is delivered along with the efficiency and effectiveness of that delivery (Marley, Collier, and Goldstein 2004). The areas of process quality were administrative processes, patient flow, patient safety and health, nurse/ assistant, and care provider. The four overall patient satisfaction questions in the survey were: "1) overall cheerfulness of our practice; 2) how well the staff worked together to care for you; 3) overall rating of care you received during visit; and 4) likelihood of you recommending our practice to others." 


\section{Description of Sample}

The survey results are reported on a fiscal year basis. The survey data used for this study are from July 1, 2011 to June 30,2012 . The survey was sent to 6,824 respondents for individual patients who had a visit to a medical group clinic. Thirty-seven surveys were returned as undeliverable. The response rate was approximately 22.2 percent. There were 1,515 respondents and 1,385 usable surveys, or a usable rate of 20.2 percent. If there were 10 or more unanswered questions by an individual respondent, the entire respondent's information was removed from the data set. The authors removed 130 respondents' information. Because of the size of the data set, there was sufficient data to develop statistically significant models. A summary of the respondent's demographic characteristics are provided in Table 1. For gender, the survey respondents were 64.7 percent (896) female and 35.3 percent (489) male. For individuals under the age of 18 , the survey was completed by someone else. More than 60 percent of the respondents were over the age of 55 , which could be indicative of a nonrespondent bias. The demographic of the nonrespondents is unknown.

\section{Accounting for Missing Observations}

An observation that had greater than 10 missing values was removed from the data set. Missing values for the 36 attitudinal questions were imputed using the average for those questions. Confirmatory factor analysis (CFA) was performed before and after accounting for missing variables, and there were minimal differences in the results.

\section{Variable Descriptions}

There are three types of variables in the model: independent, mediating, and dependent. The independent and mediating variables are consider exogenous or predictors. The exogenous variables are based on a review of those process attributes that are related to service quality in a healthcare setting. The dependent, or endogenous, variables are based on Press Ganey and

\begin{tabular}{l} 
Table 1 Demographic characteristics \\
\begin{tabular}{|l|c|c|}
\hline Demographic variable & $\mathbf{n}$ & $(\%)$ \\
\hline Gender & \multicolumn{2}{|c|}{} \\
\hline Male & 489 & $35.3 \%$ \\
\hline Female & 896 & $64.7 \%$ \\
\hline & 1,385 & $100.0 \%$ \\
\hline Age & 129 & $9.3 \%$ \\
\hline$<18$ & 85 & $6.1 \%$ \\
\hline $18-24$ & 88 & $6.4 \%$ \\
\hline $25-34$ & 82 & $5.9 \%$ \\
\hline $35-44$ & 151 & $10.9 \%$ \\
\hline $45-54$ & 285 & $20.6 \%$ \\
\hline $55-64$ & 302 & $21.8 \%$ \\
\hline $65-74$ & 262 & $18.9 \%$ \\
\hline+75 & 1 & $0.1 \%$ \\
\hline Missing & 1,385 & $100.0 \%$ \\
\hline & & \\
\hline &
\end{tabular} \\
\hline
\end{tabular}

UP Health Systems Portage, indicating that these were overall patient satisfaction measures. The 20 independent, 12 mediating, and four dependent variables are listed in Tables 2, 3, and 4, respectively.

The independent, mediating, and dependent variables were measured on an interval scale (five-point Likert scale) during the fiscal year 2012. Each variable is a dimension of the constructs identified in the initial model and stated in the earlier tables. The data source was from the Medical Practice Survey created by Press Ganey. Medical practices include all family practice and specialty clinics, including express care, in 18 locations, with 12 locations receiving greater than 10 responses and nine with greater than 100 responses. There are a total of 13 different specialty clinics, and five family practice clinics. The latter had the fewest number of responses, with specialty clinics yielding the greatest number of responses.

\section{Descriptive Statistics}

Descriptive statistics, including mean and standard deviation, for each variable were computed. This preliminary analysis allowed the authors to better understand the underlying variables in the model. The descriptive statistics are shown in the Appendix. 


\section{Table 2 Independent variables}

\begin{tabular}{|l|c|}
\hline \multicolumn{2}{|l|}{ Administrative processes } \\
\hline Ease of getting clinic on phone & $\mathrm{al}$ \\
\hline Our helpfulness on the telephone & $\mathrm{a} 2$ \\
\hline Our promptness in returning calls & $\mathrm{a} 3$ \\
\hline Convenience of our office hours & $\mathrm{a} 4$ \\
\hline Ease of scheduling appointments & $\mathrm{a} 5$ \\
\hline Courtesy of person scheduling appointments & $\mathrm{a} 6$ \\
\hline Courtesy of registration staff & $\mathrm{a} 7$ \\
\hline Patient flow & \\
\hline Speed of registration process & $\mathrm{vl}$ \\
\hline Information about delays & $\mathrm{v} 2$ \\
\hline Wait time at clinic & $\mathrm{v} 3$ \\
\hline Waiting area comfrot/pleasantness & $\mathrm{v} 4$ \\
\hline Wait before going to exam room & $\mathrm{v} 5$ \\
\hline Exam room comfort/pleasantness & $\mathrm{v} 6$ \\
\hline Wait in exam room to see CP & $\mathrm{v} 7$ \\
\hline Patient safely and health & \\
\hline How well staff protect safety & $\mathrm{i} 1$ \\
\hline Our sensitivity to patients' needs & $\mathrm{i} 2$ \\
\hline Our concern for patients' privacy & $\mathrm{i} 3$ \\
\hline Cleanliness of our practice & $\mathrm{i} 4$ \\
\hline Pain controlled & $\mathrm{i} 5$ \\
\hline Safety/security felt at practice & $\mathrm{i} 6$ \\
\hline & \multicolumn{2}{|c}{} \\
\hline
\end{tabular}

\section{Table 3 Mediating variables}

\section{Nurse/Assistont}

\begin{tabular}{|l|l|}
\hline Friendliness/courtesy of nurse/asst & $\mathrm{nl}$ \\
\hline Concern of nurse/asst for problem & $\mathrm{n} 2$ \\
\hline
\end{tabular}

\section{Care provider}

Friendliness/courtesy of $C P$

\begin{tabular}{l|l}
$\mathrm{CP}$ explanations of prob/condition & $\mathrm{cp} 2$
\end{tabular}

\begin{tabular}{l|l}
$\mathrm{CP}$ concern for questions/worries & $\mathrm{cP} 3$
\end{tabular}

\begin{tabular}{l|l}
$\mathrm{CP}$ efforts to include in decisions & $\mathrm{cp} 4$
\end{tabular}

\begin{tabular}{l|l}
$\mathrm{CP}$ information about medications & $\mathrm{cp} 5$
\end{tabular}

\begin{tabular}{l|l}
$C P$ instructions for follow-up care & $c p 6$
\end{tabular}

\begin{tabular}{|l|l}
$\mathrm{CP}$ spoke using clear language & $\mathrm{CP} 7$ \\
\hline
\end{tabular}

Time CP spent with patient

Patients' confidence in $\mathrm{CP}$

Likelihood of recommending $C P$

\section{Table 4 Dependent variables}

\begin{tabular}{|c|c|}
\hline Overall assessment & \\
\hline Cheerfulness of practice & ol \\
\hline Staff worked well together & 02 \\
\hline Care received during visit & 03 \\
\hline Likelihood of recommending practice & 04 \\
\hline
\end{tabular}

\section{Confirmatory Factor Analysis}

CFA was performed to arrive at a parsimonious representation of associations among service quality and patient satisfaction variables. CFA evaluated a priori hypothesis regarding the number of factors and which observed variables would load on these factors (Byrne 2001; Ganey 2010). This confirmed the prior analysis completed by Press Ganey (Ganey 2010). After completing the CFA, a model of hypothesized relationships between latent variables (constructs) was proposed and tested using SEM.

\section{Measurement Constructs}

The factor structure was predetermined based on prior analysis conducted by Press Ganey. The constructs included care provider, administrative processes, patient flow, patient safety and health, and nurse/assistant. All but three of the variables loaded on the factors. This was a slight difference from the original factor loadings presented in the Press Ganey report. The questions that did not load on any constructs are shown in Table 5. However, the authors added another construct, termed overall, to determine if a latent variable existed for the four observed overall patient satisfaction variables. All observed variables loaded on the overall satisfaction construct (see Table 6). This was a new construct and was considered as endogenous.

\section{Measurement and Analysis Procedure}

Press Ganey provided a summary of their CFA and it was validated in this study arriving at identical latent variables with slight differences in the numerical factor

\section{Table 5 Variables that did not load on constructs}

\begin{tabular}{|c|l|}
\hline i5 & How well your (the patient's) pain was controlled \\
\hline v6 & Comfort and pleasantness of the exam room \\
\hline v1 & Speed of the registration process \\
\hline
\end{tabular}

\section{Table 6 Overall patient satisfaction construct}

\begin{tabular}{|c|l|}
\hline 01 & Overall cheerfulness of our practice \\
\hline 02 & How well the staff worked together to care for you \\
\hline 03 & Overall rating of care received during visit \\
\hline 04 & $\begin{array}{l}\text { Likelihood of your recommending our practice to } \\
\text { others }\end{array}$ \\
\hline
\end{tabular}


loading results and a few dimensions that did not load (see Table 5). Because of the large number of observed variables in the model, Number Crunching Statistical Software (NCSS) and IBM SPSS were used to perform the CFA. Results were consistent. This formed the basis for the latent variables to develop the path diagram in SPSS Analysis of Moments Structure (AMOS), version 22. Since the factor structure was known, this represented the starting basis for developing the SEM. A two-step approach was applied: 1) CFA; and 2) SEM analysis. SEM, using AMOS, was applied to estimate the relationships in the path diagram and determine the statistical significance of each association. The authors used maximum likelihood estimation to obtain parameter estimates, which is the most common method (Sanchez-Hernandez, Houseman, and Ryan 2009). The assumptions of linearity and normal distribution are appropriate for the data and were confirmed in preliminary analysis. SEM estimates a series of interrelated dependence relationships simultaneously using latent constructs (Cheng 2001).

The authors posit that patients tend to infer the level of technical quality based on nontechnical aspects such as administrative processes, patient flow, and patient safety and health, along with the care received from the primary care provider and/or nurse/assistant (Badri, Samaa, and Ustadi 2009). It is conjectured that nontechnical quality drives overall patient satisfaction through attitudes and opinions regarding the behavioral attributes experienced through contact with the care provider and nurse/assistant.

\section{STAIISTICAL ANALYSIS OF RESULTS}

\section{Descriptive Statistics Results}

The mean of each of the questions ranged from 4.5 to 4.8 out of 5 , with standard deviations for all questions of less than 1. Given that UP Health Systems Portage has received a number of quality awards and accolades, this was not surprising. As indicated earlier, the high percentage of patients in the over 55 age category may also skew the data. The survey was a mail survey, and this could be a factor for the lower response rate by those younger than 55 who typically prefer Web-based surveys.

\section{Analysis of Correlations Between Variables Used in the Model}

Prior to performing CFA, an evaluation of key performance metrics Phi, Bartlett Test, and probability was conducted. Phi, also referred to as Gleason-Staelin redundancy, measures the interrelationship of variables. Phi was $\phi=0.52$, indicating there is correlation among the variables. This indicates there is an obvious structure in the data, which is important to further analyze. Bartlett's sphericity test was applied to test the null hypothesis that the correlation matrix is an identity matrix (all correlations are zero). The Bartlett test was 42310.26 with $\mathrm{df}=496$. The probability was zero, therefore indicating it is appropriate to perform CFA on the data (Cengiz and Kirkbir 2007).

\section{Results - Confirmatory Factor Analysis}

In the authors' study, there were 32 original dimensions developed from five constructs, including predictor and mediator variables (see Tables 2 and 3 ). After applying varimax (orthogonal) rotation, 29 of the original dimensions loaded on five factors (see Table 7). Rotation was applied to allow for a more interpretable solution prior to the application of SEM. The criterion for the number of factors extracted was determined by eigenvalues greater than one and total variance explained of at least 5 percent. In defining the factors, the factor loadings matrix was examined and factor loadings of \pm 0.55 were deemed significant because the sample size was over 100 (Hair et al. 2009). The factor structure was confirmed based on the previous analysis conducted by Press Ganey. The total amount of variation explained is 74.04 percent.

The same conceptual meaning is shared by each of the factors in the structure. This is important from an interpretability perspective since not all models have loads that make sense and measure related observed variables. 


\section{Table 7 Confirmatory factor analysis results}

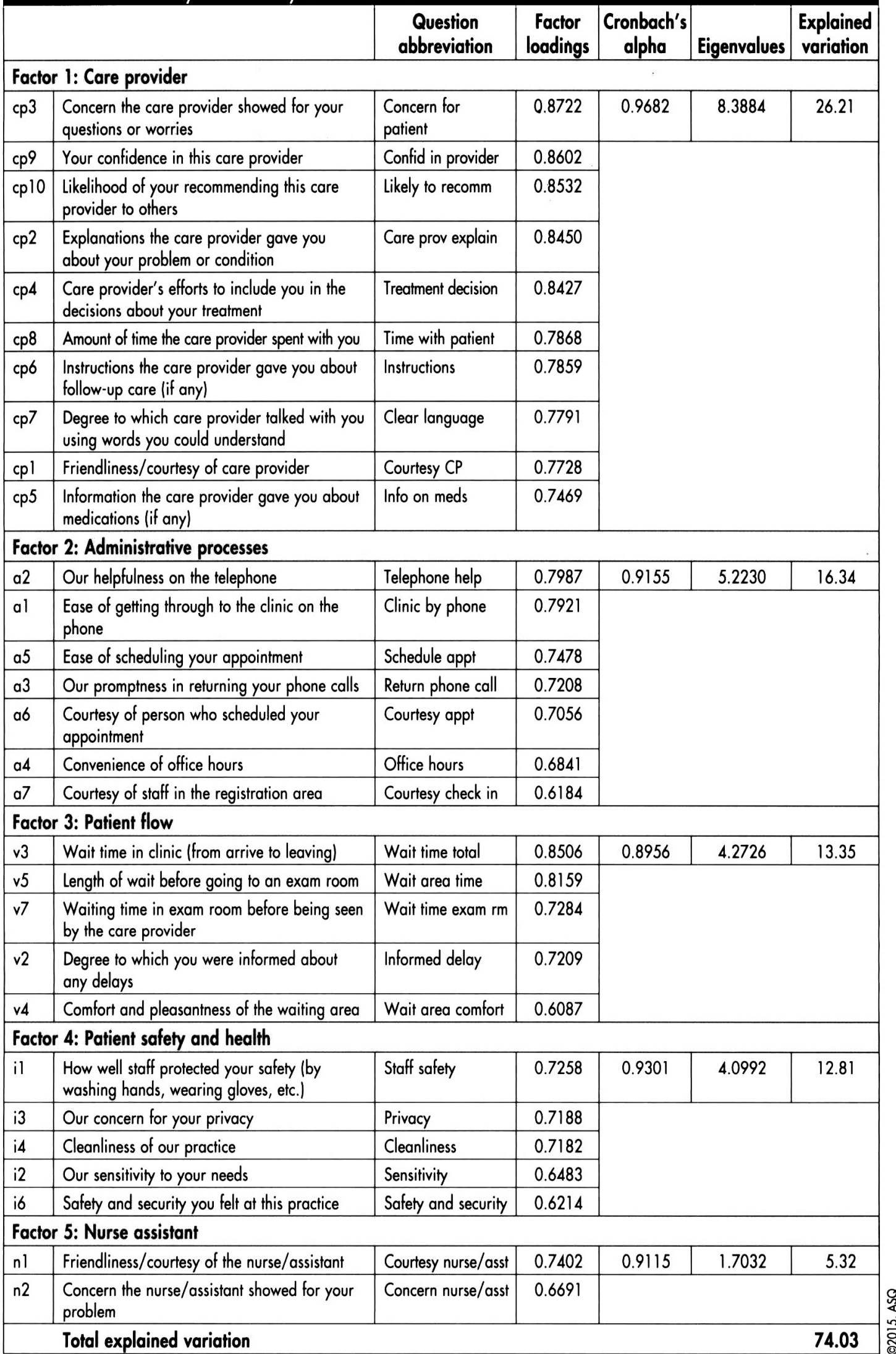




\section{Confirmatory Factor Analysis Model Fit}

The amount of variation explained by the model is a key determinant in the model fit. As indicated earlier, the amount of variation explained was 74.04 percent, accounting for a high percentage of variation. Individual factor loadings ranged from 0.61 to 0.87 . This represents an important step prior to further modeling using SEM. All but three items loaded on the factors.

Cronbach's alpha (or coefficient alpha) assesses the internal consistency coefficients and reliability. The acceptable lower limit for Cronbach's alpha is 0.70 (Robinson, Shaver, and Wrightsmann 1991; Robinson and Shaver 1973). Through this item analysis, all factors were individually analyzed and calculated alpha values are above 0.70 (see Table 7). This is indicative of the internal consistency of each of the factors. All five factors exceeded the minimum value of 0.70 , thereby indicating a high level of internal consistency and reliability.

The construct validity, or structure, was confirmed initially by Press Ganey and again by the authors' study. This confirmed the appropriate grouping of questions in the survey instrument as well as validated the factor structure that emerged with appropriate characterization of latent variables.

\section{Structural Equation Model Model Fit}

A review of the standardized residuals was conducted to identify any residuals that would considerably under-explain (above +4 ) or over-explain (below -4) relationships between two variables (Hair et al. 2009). Even though the observed variables loaded on a latent construct, if the standardized residuals were outside the parameters, they were removed from the SEM. By removing these variables, the model fit improved. This resulted in two overall patient satisfaction observed variables being removed (01 and 02 ), and one patient flow observed variable (v4). By removing these three variables, the $\chi^{2}$ value was reduced and other fit measures improved.

The measurement model yielded a $\chi^{2}$ value, which was unacceptable. However, it is well documented that the $\chi^{2}$ is sensitive to large samples that may result in the false rejection of a well-fitting model (Badri, Samaa, and Ustadi 2009). Because of the large sample size $(1,385)$, other indices such as goodness-of-fit index (GFI), adjusted goodness-of-fit index (AGFI), and standardized root mean square residual (SRMR) cannot be relied upon. Even if the $\chi^{2}$ value were acceptable, it is recommended that other goodness-of-fit indices also be evaluated. Root mean squared error of approximation (RMSEA) represents the degree to which lack of fit is due to misspecification of the model tested versus being due to sample error (Hair et al. 2009 6e, 748). Hair et al. (2009) indicate that a value of 0.10 or less for RMSEA is considered acceptable. Other researchers indicate that less than 0.08 is a fair fit, with 0.00 indicating a perfect fit (Sousa and Kwok 2006). In this model, the RMSEA is 0.072 , indicating it is considered acceptable (Malhotra 2010; Hair et al. 2009). Comparative fit index (CFI) represents the improvement of fit of the specified model over a baseline model in which all variables are constrained to be uncorrelated (Hair et al. 2009, 650). Hair et al (2009) indicate that the CFI should exceed 0.90 for a model of this size and complexity. The CFI for the model is 0.932 , thereby exceeding the threshold. Normed fit index (NFI), relative fit index (RFI), Tucker-Lewis index (TLI), and incremental fit index (IFI) all exceed 0.90 and are $0.924,0.916,0.925$, and 0.932 , respectively (Hair et al. 2009; Kline 1998; Byrne 2001). These measures indicate that the model is a good approximation of the data that it represents (Raykov and Marcoulides 2000). In other words, it is a strong fit as they are close to 1 (Raykov and Marcoulides 2000). The standardized coefficient estimates, p-value, and hypotheses outcome (results) are noted in Table 8.

The discussion of results of the hypothesized model provide further information about the output from the model.

\section{DISCLSSION OF RESULTS OF HYPOTHESIZED FRAMEWORK}

SEM was used to examine the relationships between independent (exogenous), mediating, and dependent (endogenous) latent variables. The SEM and 
Table 8 Maximum likelihood estimates, p value, and outcome of hypotheses test

\begin{tabular}{|c|c|c|c|}
\hline Path & $\begin{array}{l}\text { Standardized } \\
\text { regression } \\
\text { weights }\end{array}$ & p-value & Result \\
\hline Administrative processes $\rightarrow$ Care provider & -0.002 & 0.943 & H4 is not supported \\
\hline Administrative processes $\rightarrow$ Nurse assistant & 0.229 & $* * *$ & H5 is supported \\
\hline Patient How $\rightarrow$ Care provider & 0.106 & $* * *$ & H6 is supported \\
\hline Patient flow $\rightarrow$ Nurse assistant & 0.112 & *** & $\mathrm{H7}$ is supported \\
\hline Patient safety and health $\rightarrow$ Care provider & 0.697 & $* * *$ & H8 is supported \\
\hline Patient safety and health $\rightarrow$ Nurse assistant & 0.540 & *** & H9 is supported \\
\hline Care provider $\rightarrow$ Overall & 0.662 & $* * *$ & $\mathrm{H} 10$ is supported \\
\hline Nurse assistant $\rightarrow$ Overall & 0.337 & *** & $\mathrm{HIl}$ is supported \\
\hline
\end{tabular}

The primary service is the initial meeting with the nurse/assistant followed by the care provider. Because most of the administrative processes occur prior to the patient's visit, with the exception of registration upon arrival at the clinic, it is not surprising that the standardized path coefficients for the mediating latent variables were not statistically significant regarding the

hypothesized relationships are presented in Figure 1. After applying SEM and removing dimensions (variables) to improve the path analytical model fit, the results are shown in Figure 2.

The latent constructs of administrative processes, patient flow, and patient safety and health are highly correlated, as shown in the arced, two-headed errors. Although some path models do not show the correlations between the exogenous variables, they do have an impact on the overall path model. As expected, they are highly correlated because of the different dimensions and attributes associated with behavioral and administrative aspects of service quality associated with patient visits to a medical clinic.

Administrative processes precede the interaction of the patient with the primary service transaction. impact of administration processes on care provider $\left(\gamma_{1}=-0.002, p=0.943\right)$. Generally, if a patient needs to contact a medical professional prior to his or her visit, it is more than likely to be a nurse/assistant as opposed to a care provider. Administrative processes (H2) does have a statistically significant impact on nurse/assistant $\left(\gamma_{2}=0.23, \mathrm{p}<0.001\right)$. This is not surprising because there may be some contact with a nurse/assistant as a part of arranging the patient's visit that would account for this relationship.

Patient flow on care provider (H3) and patient flow on nurse/assistant (H4) are similar and weak $\left(\gamma_{3}=0.11, p<0.001\right)$. Patient safety and health (H5) and (H6) respectively, have a strong statistically significant association with both care provider $\left(\gamma_{5}=0.70, p<0.001\right)$ and nurse/assistant

Figure 2 Measurement model with standardized estimates

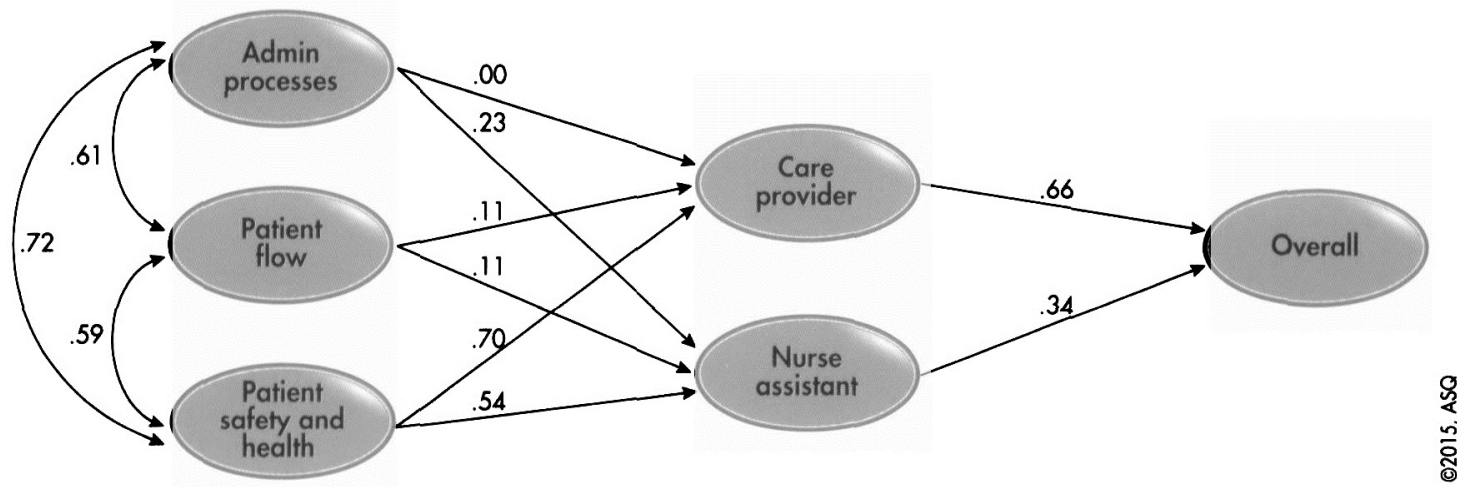


$\left(\gamma_{6}=0.54, p<0.001\right)$. This may be interpreted to mean that the patient safety and health related to patients' primary concerns are being addressed by the care provider and the nurse/assistant.

Care provider and nurse/assistant latent variables had a positive impact on overall patient satisfaction, with care provider $(\mathrm{H} 7)$ at $\beta_{1}=0.66, \mathrm{p}<0.001$ and nurse/assistant (H8) at $\beta_{2}=0.34, p<0.001$. Therefore, care provider and nurse/assistant are significant predictors of overall patient satisfaction. Because the care provider may spend the greatest amount of time with the patient, it would be expected that the impact on overall patient satisfaction would be greater. This would also affirm the earlier discussion regarding the strong relationship between patient safety and health and care provider. All but one of the path coefficients (H1) in the model were statistically significant as hypothesized.

\section{DISCUSSION AND IMPLICATIONS OF THE STUDY}

Implicit in patient satisfaction studies conducted by healthcare organizations is the importance of delivering high-quality services that generate highly satisfied and loyal patients (Scotti, Harmon, and Behson 2007). The preliminary model of healthcare service quality and overall patient satisfaction provides initial results for both practitioners and researchers to consider ways to better use the data to make decisions regarding continuous improvement activities (Douglas and Fredendall 2004; Elg, Broryd, and Kollberg 2013). Most prior work regarding healthcare service quality and overall patient satisfaction has focused on inpatient hospital stays (Andaleeb 2001; Cengiz and Kirkbir 2007; Drupsteen, Van der Vaart, and Van Donk 2013), specialized care (Chang et al. 2006), or management and employees' views of service quality (Scotti, Harmon, and Behson 2007; Ancarani, DiMauro, and Giammanco 2011; Fottler et al. 2006). This study is a unique contribution because the focus is on medical practice clinics in a rural setting. These medical clinics range from general care (that is, family practice, express care, and so on) to specialty clinics (that is, orthopaedics, pediatrics, and so on). This study extends prior academic research conducted in the area of patient satisfaction.

\section{Nanagérial Implications}

Understanding the impact of quality management practices on overall patient satisfaction is critical because ultimately it will impact firm performance (Carter, Lonial, and Raju 2010). The role of continuous quality improvement is the responsibility of the executive team, primarily the: 1) chief nursing officer (vice president of nursing, director of nursing); and 2) vice president of quality, vice president of patient care, quality and safety or clinical systems analysis manager, or director of quality improvement (Boyer, Gardner, and Schweikhart 2012). At UP Health Systems Portage, LLC, this role is held by Elizabeth MacInnes, vice president of quality. Because the survey data had small variation as measured by the standard deviation, along with relatively high means, increasing the averages and reducing the standard deviation would position this healthcare organization to improve its overall rankings among similar size providers.

Patients should be aware of the favorable trends experienced by this organization through regular press releases and reporting. Employees should continue to be commended for their outstanding service quality and continuing high level of patient satisfaction. Based on the model, managers can understand which dimensions and constructs are greater predictors of overall patient satisfaction.

The models and business analytics were presented to UP Health Systems Portage executives to understand how they would apply the additional information in the context of their continuous improvement activities. MacInnes stated "Maintaining high quality and service remain at the forefront. UP Health Systems Portage is continually seeking ways to improve its services and recognizes value in various sources of information to provide guidance and direction for quality and service initiatives. This research serves as a great reference point to support our service improvement efforts" (MacInnes 2014). 
As healthcare providers seek additional data, this allows them to keep their eye on the target/goals and ensure that the employees and managers do not lose sight of the customer, in this case the patient. With healthcare organizations facing pressure from governmental and regulatory agencies at an increasing rate, it is too easy to become busy and lose focus. "Especially in a time period where there are mergers and acquisitions occurring at a rapid rate, it is very challenging to keep the staff enthusiastic and passionate about providing great customer service all the time" (MacInnes 2014).

\section{Limitations of the Research}

In reviewing the results of this study, there are several limitations. The majority of the survey respondents were over the age of 55 , and a higher proportion of the respondents were female. In addition, a nonresponse bias for the survey may impact the overall results. For example, the length of the survey and lack of incentive to complete the survey may affect who responds. There is also potential nonresponse bias due to the use of mail surveys versus electronic surveys. It is likely that younger respondents will respond more readily to an electronic than a paper survey. Currently, UP Health Systems Portage administers their patient satisfaction surveys entirely by mail. At this time there are no plans to offer both mail and electronic surveys or move to electronic surveys exclusively.

Ford, Bach, and Fottler (1997) note that due to the timing delay the results of a mailed survey may make it difficult for patients to remember the details of patient flow, there may be an unconscious bias due to other experiences with the same service provider, and the respondents may not understand the intent of the survey questions. However, as also noted by Ford, Bach, and Fottler (1997), mail surveys allow a service provider to gather representative and valid samples that can be used for a statistical comparison of demographics and clinics. The time between the visit and the survey allows patients to reflect upon their service experience. Moreover, seeking the patient's input indicates both the service provider's interest in improving the service and the value he or she places on the patient's opinion.

\section{Considerations to Improve Response Rate}

The results of this study provide insights into the impact of service quality on patient satisfaction. Given the higher average age of respondents, the healthcare organization should consider using electronic surveys as a means to increase the response rate overall and among younger patients. This can be accomplished by sending the paper survey and including a URL with an access code and identification number to facilitate the ability to add nonsurvey information (that is, date of visit, clinic ID, doctor $\mathrm{ID}$, age, gender, and so on) to the questionnaire responses, or sending an email to recent patients with access information included.

If healthcare organizations are unwilling to use electronic, Internet-based surveys, an alternative is to provide the questionnaire to the patient upon departure with a stamped, self-addressed envelope for return. Another option for improving the return of surveys is to have a prominently displayed sealed box near the exit of the facility for the patient to leave the completed questionnaire. A positive aspect of this approach is that employees are visibly aware of patients who have completed the survey prior to leaving, and knowing that a survey will be completed will increase their focus on improving the level of service they provide above and beyond what may be provided if the surveys were administered at a later date through the mail. A downside to this approach is that a patient with an unfavorable experience will be more likely to respond negatively when the service is fresh in his or her mind than if he or she were to receive the survey at a later date in the mail.

Some individuals will not complete a survey if they have a poor experience. They may throw it away when received in the mail and choose not to go back to the provider. They may believe it is too much trouble and a waste of time to complete a survey when they view that nothing will change as a result of completing the survey. Thus, a healthcare organization may lose patients without ever knowing why.

For a more balanced response, agencies might want to consider using focus groups and providing an 
incentive for participating. This would increase the patient involvement in the service delivery strategy and aid in the improvement of service quality and patient satisfaction (Harvey 1998).

\section{CONCLLSIONS}

In a people-centric and dependent organization, the business and operations strategy and related metrics must emphasize patient satisfaction and consistent service quality. Even in rural communities, patients have access to local and regional providers and competitors. Although the perception may be that choices are limited, in a mobile society, individual consumers are able to make selections that balance quality and cost. The rapid growth in the global healthcare sector provides even more opportunities for meeting patient needs for those who are able and willing to travel and can accept the potential risk. Telemedicine is also experiencing rapid growth in the healthcare sector, especially in a rural setting.

This study highlighted the application of multivariate analysis to extend the business analytics of a healthcare organization beyond descriptive statistics. Further, this research created an SEM to better understand the factors that predict overall patient satisfaction. It is acknowledged that the effective use of patient satisfaction metrics can create a competitive advantage for a healthcare organization (Urden 2002). The voice of the patient allows decision makers to be informed about what is important to their customers. Service quality has multiple dimensions with varying degrees of significance to the patient. The entry point for the service encounter begins with the administrative processes. The ability to be able to secure an appointment time with the preferred provider is the first step in the process. Once the patient arrives, he or she continues to interact with personal representatives and expect courtesy and helpfulness (Russell, Johnson, and White 2014). Once the patient is checked in, the patient flow and patient safety and health processes begin. After the initial wait in the waiting room, the patient is called by the nurse/assistant, which results in the commencement of a concurrent process. The nurse/assistant is a facilitator of different aspects of the patient flow and patient safety and health processes. At this point in the service system, the patient is seeking empathy, friendliness, courtesy, and the feeling that he or she is truly being cared for (Chahal and Mehta 2013). After the nurse/assistant have provided their service, the care provider plays a major role in the patient encounter. In fact, close to a third of the survey questions are based on the culmination of the overall patient encounter with the care provider, giving the greatest weight to overall patient satisfaction. Explicit or implicit in the survey questions is the communication dimension. Past research has emphasized the importance of strong communication skills for care providers (Naidu 2009). The results of the model support the overall strength of the relationship and the predictability of patient satisfaction from the care provider service encounter.

The authors studied one year of data, which gave them a snapshot in time. To understand whether UP Health Systems Portage has a history of strong patient satisfaction, it is important to extend the research to a longer period of time and to study multiple years of survey results.

\section{Future Research}

Studying one year of data provides initial insights regarding predictors of overall patient satisfaction. To be more effective, it is important to conduct a longitudinal study over a longer period of time to determine if the same relationships hold true, to understand if improvements have increased overall patient satisfaction, and to study different demographic groups. Because the mix of services provided and patients taking the survey will vary from one year to the next, it is essential to understand if consistency exists and if continuous improvement efforts have been effective. Time lags in studying data can result in delays to organizationwide improvement efforts. Continually reviewing patient satisfaction data and taking action will result in the highest levels of service provided by an organization. 


\section{ACKNOWLEDGMENT}

The authors are grateful to UP Health System Portage and Press Ganey for providing them with their survey results and allowing them to extend the work already completed by Press Ganey. The authors would like to thank the following individuals at UP Health System Portage: Elizabeth Macinnes, vice president quality management, Lisa Kaarto, and UP Health System market president James Bogan

\section{REFERENCES}

Ancarani, A., C. DiMauro, and M. D. Giammanco. 2011. Patient satisfaction, managers' climate orientation and organizational climate. International Journal of Operations \& Production Management 31, no. 3:224-250.

Andaleeb, S. S. 2001. Service quality perceptions and patient satisfaction: A study of hospitals in a developing country. Social Science \& Medicine 52:1359-1370.

Babbar, S., and X. Koufierous. 2008. The human element in airline service quality: Contact personnel and the customer. International Journal of Operations \& Production Management 28, no. $9: 804-830$

Badri, M. A., and S. T. Attia. 2008. Testing not-so-obvious models of healthcare quality. International Journal of Health Care Quality Assurance 21, no. 2:159-174.

Badri, M. A., A. Samaa, and A. M. Ustadi. 2009. Healthcare quality and moderators of patient satisfaction: Testing for causality. International Journal of Health Care Quality Assurance 22, no. $4: 382-410$

Baron, R. M., and D. A. Kenney. 1986. The moderator-mediator variable distinction in social psychological research: Conceptual, strategic, and statistical considerations. Journal of Personality and Social Psychology 51:1173-1182.

Behara, R. S., W. W. Fisher, and J. G. A. M. Lemmink. 2002. Modelling and evaluating service quality measurement using neural networks. International Journal of Operations \& Production Management 22, no. 10:1162-1185.

Boyer, K. K., J. W. Gardner, and S. Schweikhart. 2012. Process quality improvement: An examination of general vs. outcomespecific climate and practices in hospitals. Journal of Operations Management 30, no. 4:325-339.

Brady, M. K., and J. J. Jr. Cronin. 2001. Some new thoughts on conceptualizing perceived service quality: A hierarchical approach. Journal of Markefing 65:34-49.

Buyukozhan, G., G. Cifci, and S. Guleryuz. 2011. Strategic analysis of healthcare service quality using fuzzy AHP methodoogy. Expert systems with applications 38:9407-9424.

Byrne, B. M. 2001. Structural equation modeling with AMOX. Mahwah, NJ: Lawrence Erlbaum Associates.
Canel, C., and E. Fletcher. 2001. An analysis of service quality at a student health center. International Journal of Health Care Quality Assurance 14, no. 6/7:260-267.

Carlucci, D., P. Renna, and G. Schiuma. 2013. Evaluating service quality dimensions as antecedents to outpatient satisfaction using back propagation neural network. Health Care Management Science 16:37-44.

Carman, J. M. 2000. Patient perceptions of service quality: Combining the dimensions. The Journal of Services Marketing 14, no. 4:337-352

Carson, P. P., K. D. Carson, and C. W. Roe. 1998. Toward understanding the patient's perception of quality. Health Care Supervisor 16, no. 3:36-42.

Carter, R. E., S. C. Lonial, and P. S. Raju. 2010. Impact of quality management on hospital performance: an empirical examination. Quality Management Journal 17, no. 4:8-24.

Cengiz, E., and F. Kirkbir. 2007. Customer perceived value: The development of a multiple item scale in hospitals. Problems and Perspectives in Management 5, no. 3:252-286.

Chahal, H., and H. Mehta. 2013. Developing patient satisfaction construct for public and private health care sectors. Journal of Services Research 13, no. 2:7-30.

Chahal, H., and R. D. Sharma. 2004. Managing health care service quality in primary health care centre. Metamorphosis 3 , no. 2:112-131.

Chang, C., H. Weng, H. Chang, and T. Hsu. 2006. Customer satisfaction in medical service encounters: $A$ comparison between obstretrics and gynecology patients and general medical patients. Journal of Nursing Research 14, no. 1:9-23

Cheng, E. W. L. 2001. SEM being more effective than multiple regression in parsimonious model testing for management development research. Journal of Management Development 20, no. 7:650-667.

Choi, K. S., W. H. Cho, S: Lee, H. Lee, and C. Kim. 2004. The relationships among quality, value, satisfoction and behavioral intention in health care provider choice: A South Korean study. Journal of Business Research 57:913-921.

Dagger, T. S., J. C. Sweeney, and L. W. Johnson. 2007. A hierarchical model of health service quality: Scale development and investigation of an integrated model. Journal of Service Research 10 , no. 2:123-142.

Douglas, T. J., and L. D. Fredendall. 2004. Evaluating the Deming management method of total quality services. Decision Sciences 35 , no. 3:393-422

Drupsteen, J., T. Van der Vaart, and D. Van Donk. 2013 Integrative practices in hospitals and their impact on patient flow. International Journal of Operations \& Production Management 33, no. 7:912-933. 
Elg, M., K. Broryd, and B. Kollberg. 2013. Performance measurement to drive improvements in healthcare practice. International Journal of Operations \& Production Management 33, no. 11/12:1623-1651.

Ford, R. C., S. A. Bach, and M. D. Fottler. 1997. Methods of measuring patient satisfaction in health care organizations. Health Care Management Review 22, no. 2:74-89.

Fottler, M. D., D. Dickson, R. C. Ford, K. Bradley, and L. Johnson. 2006. Comparing hospital staff and patient perceptions of customer service: A pilot study utilizing survey and focus group data. Health Services Management Research 19:52-66.

Ganey, P. 2010. Medical practice survey psychometrics. Chicago, IL: Press Ganey Associates, Inc.

Geberemichael, S. G., G. Z. Metaferia, G. M. Takele, and J. C. Johnston. 2011. Patient satisfaction with outpatient neurology services: A momentum for improvement. Journal of Neurological Sciences 303:128-132.

Hair, J. F., W. C. Black, B. J. Babin, and R. E. Anderson. 2009. Mulfivariate data analysis: A global perspective. Upper Saddle River, NJ: Prentice Hall.

Hall, J. A., and M. C. Dornan. 1988. Meta-analysis of satisfaction with medical care: Description of research domain and analysis of overall satisfaction level. Social Science \& Medicine 27 , no. 6:637-644.

Harvey, J. 1998. Service quality: A tutorial. Journal of Operations Management 16:583-597.

Haywood-Farmer, J. 1988. A conceptual model of service quality. International Journal of Operations \& Production Management 8, no. 6:19-29.

Kilbourne, W. E., J. A. Duffy, M. Duffy, and G. Giarchi. 2004. The applicability of SERVQUAL in cross-national measurements of health-care quality. The Journal of Services Marketing 18, no. 6/7:524-533.

Kline, R. B. 1998. Principles and practice of structural equation modeling. New York, NY: Guilford Press.

Koenig, H. F., and I. K. Kleinsorge. 1994. Perceptual measures of quality: A tool to improve nursing home systems. Hospital \& Health Service Administration 39:487-503.

Lin, B., and E. Kelly. 1995. Methodological issues in patient satisfaction surveys. International Journal of Health Care Quality Assurance 8, no. 6:32-37.

Maclnnes, E. 2014. Interview. Vice president of quality, UP Health Systems Portage. Hancock, MI.

MacKinnon, D. P. 2012. Integrating mediators and moderators in research design. Research on Social Work Practice 21, no. 6:675-681.

Maddigan, S. L., S. R. Majumdar, and J. A. Johnson. 2005. Understanding the complex associations between patient-provider relationships, self-care behaviors, and health-related quality of life in type 2 diabetes: a structural equation modeling approach. Quality of Life Research 14:1489-1500

Malhotra, H. K. 2010. Marketing research: An applied orientation, sixth edition. New Jersey: Pearson.

Mannon, M. 2014. Lean healthcare and quality management: The experience of ThedaCare. Quality Management Journal 21, no. 1:7-10.

Marley, K. A., D. A. Collier, and S. M. Goldstein. 2004. The role of clinical and process quality in achieving patitent satisfaction in hospitals. Decision Sciences 35, no. 3:349-369.

Mazor, K. M. B. E. Clauser, T. Field, R. A. Yood, and J. H. Gurwitz. 2002. A demonstration of the impact of response bias on the results of patient satisfaction survey. Health Services Research 37, no. 5:1403-1417.

McDougall, G. H. G., and T. J. Levesque. 1994. A revised view of service quality dimensions: An empirical investigation. Journal of Professional Senvices Marketing 11, no. 1:189-209.

Naidu, A. 2009. Foctors affecting patient satisfaction and healthcare quality. International Journal of Health Care Quality Assurance 22, no. 4:366-381.

Qin, H., V. R. Prybutok, D. A. Peak, and K. W. Boakye. 2014. UCPEF: An urgent care patient satisfaction instrument. Quality Management Journal 21, no. 3:11-25.

Parasuraman, A., V. A. Zeithaml, and L. L. Barry. 1988. SERVQUAL: A multiple-item scale for measuring consumer perceptions of service quality. Journal of Retailing 64, no. 1:12-40.

Raykov, T., and G. A. Marcoulides. 2000. A first course in structural equation modeling. Mahwah, NJ: Lawrence Erlbaum Associates, Inc.

Robinson, J. P., and P. R. Shaver. 1973. Measures of psychological attitudes. Ann Arbor, Ml: Survey Research Center Institute for Social Research, University of Michigan.

Robinson, J. P., P. R. Shaver, and L. S. Wrightsmann. 1991. Criteria for scale selection and evaluation. In Measures of Personality and Social Psychological Attitudes, eds. J. P. Robinson, P. R. Shaver, and L. S. Wrightsmann. San Diego, CA: Academic Press.

Russell, R. S., D. M. Johnson, and S. W. White. 2014. Patient perceptions of quality: Analysing patient satisfaction survey. International Journal of Operations \& Production Management.

Sanchez-Hernandez, B. N., E. A. Houseman, and L. M. Ryan. 2009. Residual-based diagnostic for structural equation models. Biometrics 65:104-115.

Scolti, D. J., J. Harmon, and S. J. Behson. 2007. Links among high-performance work environment, service quality, and customer satisfaction: an extension to the healthcare sector. Journal of Healthcare Management 52, no. 2:109-125.

Soleriou, A. C., and R. B. Chase. 2000. A robust optimization approach for improving service quality. Manufacturing \& Service Operations Management 2, no. 3:264-286. 
Sousa, K. H., and O. M. Kwok. 2006. Putting Wilson and Cleary to the test: Analysis of a HRQOL conceptual model using structural equation modeling. Quality of Life Research 15:725-737.

Tucker, J. L. 2002. The moderators of patient satisfaction. Journal of Management in Medicine 16, no. 1:48-66.

Urden, L. 2002. Patient satisfaction measurement: Current issues and implications. Professional Case Management 7. no. 5:194-200.

Vogus, T. J., K. M. Sutcliffe, and K. E. Weick. 2010. Doing no harm: Enabling enacting and elaborating a culture of safely in health care. Academy of Management Perspectives 24, no. 4:60-77.

Wu, W. Y., S. W. Hsiao, and H. P. Kuo. 2004. Fuzzy set theory based decision model for determining market position and developing strategy for hospital service quality. Total Quality Management 15, no. 4:439-456.

Zandbelt, L., E. Smets, F. Oort, M. Godfried, and H. de Jaes. 2004. Satisfaction with outpatient experience. Journal of General Internal Medicine 19, no. 11:1088-1095.

\section{BIOGRAPHIES}

Dana M. Johnson is a professor of engineering and supply chain management and an adjunct professor of mechanical engineering at Michigan Technological University. Her current research focus is modeling performance measurement in healthcare operafions and optimization of biomass supply chains for alternative fuels. She has published in the Quality Management Journal, International Journol of Operations and Production Management, International Journal of Quality and Reliability Management, Biomass and Bioenergy, Journal of Environmental Management, and a number of other publications. She is a CQE, CMQ/OE, CQA, CSSGB, CPA, and CMA. Johnson can be reached by email at dana@mtu.edu.

Roberta S. Russell is a professor of business information technology at the Virginia Polytechnic Institute and State University. She is coauthor of Operations and Supply Chain Management in its eighth edition with Wiley \& Sons, and Service Operations and Management in its second edition with Prentice-Hall. Her research on service operations, scheduling, and lean have been published in the Journal of Operations Management, Decision Sciences, International Journal of Production Research, IIE Transactions, IEEE Transactions, Annals of Operations Research and others. She holds a CFPIM and a CSCP from APICS, and is the immediate past president of the APICS Foundation. 


\section{APPENDIXi DESCRIPTIVE STAIISTICS OF SLRVEY ITEMS}

\begin{tabular}{|c|c|c|c|}
\hline Variables & Variable description & Mean & $\begin{array}{l}\text { Standard } \\
\text { deviation }\end{array}$ \\
\hline \multicolumn{2}{|l|}{ Access } & 4.621 & 0.608 \\
\hline al & Ease of getting through to the clinic on the phone & 4.595 & 0.636 \\
\hline a2 & Our helpfulness on the telephone & 4.644 & 0.589 \\
\hline a3 & Our promptness in returning your phone calls & 4.491 & 0.683 \\
\hline a4 & Convenience of office hours & 4.576 & 0.627 \\
\hline a5 & Ease of scheduling your appointment & 4.569 & 0.719 \\
\hline ab & Courtesy of person who scheduled your appointment & 4.730 & 0.502 \\
\hline a7 & Courtesy of staff in the registration area & 4.739 & 0.501 \\
\hline \multicolumn{2}{|c|}{ Moving through your visit } & 4.522 & 0.679 \\
\hline vl & Speed of the registration process & 4.674 & 0.546 \\
\hline v2 & Degree to which you were informed about any delays & 4.503 & 0.712 \\
\hline v3 & Wait time in clinic (from arrive to leaving) & 4.420 & 0.785 \\
\hline v4 & Comfort and pleasantness of the waiting area & 4.567 & 0.613 \\
\hline $\mathrm{v5}$ & Length of wait before going to an exam room & 4.475 & 0.727 \\
\hline v6 & Comfort and pleasantness of the exam room & 4.535 & 0.617 \\
\hline v7 & Waiting time in exam room before being seen by the care provider & 4.479 & 0.750 \\
\hline \multicolumn{2}{|c|}{ Nurse/Assistant } & 4.750 & 0.509 \\
\hline $\mathrm{nl}$ & Friendliness/courtesy of the nurse/assistant & 4.780 & 0.481 \\
\hline n2 & Concern the nurse/assistant showed for your problem & 4.719 & 0.536 \\
\hline \multicolumn{2}{|c|}{ Care provider } & 4.717 & 0.599 \\
\hline cpl & Friendliness/courtesy of care provider & 4.781 & 0.509 \\
\hline cp2 & Explanations the care provider gave you about your problem or condition & 4.715 & 0.604 \\
\hline cp3 & Concern the care provider showed for your questions or worries & 4.707 & 0.615 \\
\hline cp4 & Care provider's efforts to include you in the decisions about your treatment & 4.716 & 0.590 \\
\hline cp5 & Information the care provider gave you about medications (if any) & 4.677 & 0.618 \\
\hline cp6 & Instructions the care provider gave you about follow-up care (if any) & 4.680 & 0.629 \\
\hline cp7 & Degree to which care provider talked with you using words you could understand & 4.763 & 0.527 \\
\hline $\mathrm{cp8}$ & Amount of time the care provider spent with you & 4.693 & 0.620 \\
\hline ep9 & Your confidence in this care provider & 4.726 & 0.618 \\
\hline cplo & Likelihood of your recommending this care provider to others & 4.715 & 0.659 \\
\hline \multicolumn{2}{|c|}{ Personal issues } & 4.700 & 0.532 \\
\hline $\mathrm{il}$ & How well staff protected your safety (by washing hands, wearing gloves, etc.) & 4.708 & 0.526 \\
\hline i2 & Our sensitivity to your needs & 4.673 & 0.573 \\
\hline i3 & Our concern for your privacy & 4.704 & 0.524 \\
\hline i4 & Cleanliness of our practice & 4.743 & 0.485 \\
\hline i5 & How well your (the patient's) pain was controlled & 4.631 & 0.578 \\
\hline i6 & Safety and security you felt at this practice & 4.739 & 0.504 \\
\hline \multicolumn{2}{|c|}{ Overall assessment } & 4.716 & 0.562 \\
\hline ol & Overall cheerfulness of our practice & 4.693 & 0.538 \\
\hline o2 & How well the staff worked together to care for you & 4.714 & 0.550 \\
\hline 03 & Overall rating of care received during visit & 4.732 & 0.545 \\
\hline 04 & Likelihood of your recommending our practice to others & 4.725 & 0.614 \\
\hline
\end{tabular}




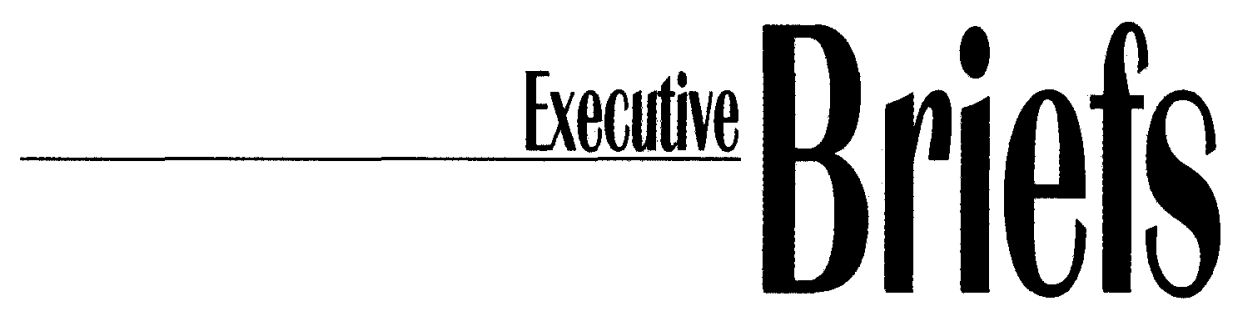

Modern Analytics and the Future of Quality and Performance Excellence (pp. 6-17). James R. Evans, University of Cincinnati

Applications of analytics have grown dramatically over the last decade, particularly in industries such as business and healthcare. Many organizations are using analytics strategically to make better decisions and improve customer and shareholder value. Analytics is changing how organizations manage. That is, tools and techniques of modern analytics are used in a variety of organization types to improve the management of customer relationships, financial and marketing activities, supply chains, and other areas. Research also suggests that organizations are overwhelmed by data and have difficulty determining how to use their data to achieve business results.

The importance of modern analytics is becoming recognized in the Baldrige Criteria and represents a noteworthy opportunity for quality managers, executives who pursue performance excellence, and academic researchers. But despite the sizeable amount of activity surrounding analytics in business, the quality profession has lagged behind analytic trends, and many opportunities exist in quality management activities for using analytics.
The successful application of analytics requires more than just knowing the tools; it requires a high-level understanding of how analytics supports an organization's competitive strategy and effective execution that crosses multiple disciplines and managerial levels. Quality professionals must understand and develop new applications of analytics, and begin to incorporate these approaches into their daily work.

\section{SEM of Service Quality to} Predict Overall Patient Satisfaction in Medical Clinics: A Case Study (pp. 18-36). Dana M. Johnson, Michigan Technological University, and Roberta S. Russell, Virginia Polytechnic Institute and State University

Patient satisfaction is an integral part of quality of care for hospitals, as well as clinics and other healthcare settings. While much research is available regarding patient satisfaction in an acute care hospital, a gap in the literature exists in predicting patient satisfaction for medical clinics, and in identifying and understanding the different attributes of service quality for patients who maintain a continuing relationship with a clinic or physician's office.

The research presented in this article addresses these shortcomings by analyzing patient satisfaction surveys from medical clinics of a rural Midwestern healthcare organization. The medical clinics include family practice, urgent care, and specialty clinics, totaling 18 different locations. Patient satisfaction surveys were created and administered by a third party. Structural equation modeling (SEM) was used to identify factors that impact patient satisfaction, and the information was used to: 1) gain a greater understanding of the factors that drive overall patient satisfaction in medical clinics; and 2) explore how metrics of patient satisfaction can foster continuous process improvement efforts.

Results of this study show that the business and operations strategy and related metrics must emphasize patient satisfaction and consistent service quality. Individual consumers are able to make choices that balance cost and quality. The voice of the patient allows decision makers to be informed about what is important to their customers. The results of this study support the overall strength of the relationship and predictability of patient satisfaction from the care provider service encounter.

Factors in the Path From Lean to Patient Safety: Six Sigma, Goal Specificity, and Responsiveness Capability (pp. 37-53). Kathleen L. McFadden, 